\title{
Effects of fluoride concentration and temperature of milk on caries lesion rehardening
}

Department of Preventive and Community Dentistry, Oral Health Research Institute, Indiana University School of Dentistry, USA

\section{A R T I C L E I N F O}

Article history:

Received 27 March 2012

Received in revised form

3 May 2012

Accepted 1 June 2012

\section{Keywords:}

Enamel caries

$\mathrm{pH}$ cycling

Rehardening

Fluoride

Milk

\begin{abstract}
A B S T R A C T
Objectives: The aim of the present in vitro study was to investigate the effects of fluoride concentration and temperature of milk on caries lesion rehardening under $\mathrm{pH}$ cycling conditions.

Methods: Incipient caries-like lesions were formed in human enamel specimens, characterized using Vickers surface microhardness (VHN) and assigned to seven treatment groups ( $n=18$ per group): fluoride was tested at five levels $\left(0,2.5,5,10,20 \mathrm{mg} / \mathrm{l}\right.$, all $22^{\circ} \mathrm{C}$ ) and milk temperature at three levels $\left(4,22,60^{\circ} \mathrm{C}\right)$, but only for $10 \mathrm{mg} / \mathrm{l} \mathrm{F}$. Lesions were $\mathrm{pH}$ cycled for $15 \mathrm{~d}(4 \times /$ daily $10 \mathrm{~min}$ milk treatments, $1 \times /$ daily $4 \mathrm{~h}$ acid challenge, remineralization in human/artificial saliva mixture). VHN of specimens were measured again and changes from lesion baseline were calculated. Subsequently, enamel fluoride uptake (EFU) was determined using the micro drill technique.

Results: Lesions responded to fluoride in a dose-response manner with higher fluoride concentrations resulting in more lesion rehardening $(20>10 \geq 5 \geq 2.5>0 \mathrm{mg} / \mathrm{l} \mathrm{F})$. Furthermore, fluoridated milk at $60^{\circ} \mathrm{C}$ was found to be more efficacious than at $4{ }^{\circ} \mathrm{C}\left(60 \geq 22>4{ }^{\circ} \mathrm{C}\right)$. EFU results were similar $\left(20>10>5>2.5 \geq 0 \mathrm{mg} / \mathrm{l} \mathrm{F} ; 60>22 \geq 4^{\circ} \mathrm{C}\right)$.

Conclusions: Both fluoride concentration and milk temperature are likely to contribute to the anti-caries potential of fluoridated milk.
\end{abstract}

(C) 2012 Elsevier Ltd. All rights reserved.

\section{Introduction}

Milk fluoridation has been shown to be an effective public health measure ${ }^{1}$ and has been recommended for target groups with high caries prevalence and poor compliance for oral hygiene in areas without water fluoridation. ${ }^{2}$ Bearing in mind that milk fluoridation is almost exclusively targeted at children in kindergartens and primary schools, one of the main tasks for the research community should be to focus on the optimization of fluoride delivery from milk to maximize its benefit/risk ratio.

Studies on the optimization of fluoride delivery have generally focused only on conventional oral care products, and these results are not necessarily translatable to fluoridated milk. Previous research on dentifrices and mouth rinses highlighted the importance of fluoride concentration vs. dose, ${ }^{3}$ exposure/brushing time and dose effects ${ }^{4}$ and frequency of fluoride exposure ${ }^{5}$ to name only a few. The temperature of fluoride application is also pertinent, however studies are few and primarily focused on the effect of temperature on in vitro enamel fluoride uptake (EFU). ${ }^{6,7}$ Increasing the temperature of fluoride delivery from rinses and dentifrices is generally impractical, and organoleptically unfavourable. However, it potentially provides a possible route for enhancing the effectiveness of fluoridated milk.

The fluoride dose-response of fluoridated milk has been studied under in situ ${ }^{8,9}$ and in vitro conditions. ${ }^{10,11}$ In situ, a

\footnotetext{
${ }^{*}$ Corresponding author at: Department of Preventive and Community Dentistry, Oral Health Research Institute, Indiana University School of Dentistry, 415 Lansing Street, Indianapolis, IN 46202, USA. Tel.: +1 317274 3983; fax: +1 3172745425.

E-mail address: flippert@iupui.edu (F. Lippert).

0300-5712/\$ - see front matter (C) 2012 Elsevier Ltd. All rights reserved.
}

This is the author's manuscript of the article published in final edited form as:

Lippert, F., Martinez-Mier, E. A., \& Soto-Rojas, A. E. (2012). Effects of fluoride concentration and temperature of milk on caries lesion rehardening. Journal of dentistry, 40(10), 810-813. https://doi.org/10.1016/j.jdent.2012.06.001 
fluoride dose-response was shown for the prevention of enamel surface softening, ${ }^{8}$ but not for the enhancement of lesion remineralization. ${ }^{9}$ Previous in vitro studies have been equally equivocal and showed a fluoride dose-dependency to lesion remineralization ${ }^{10}$ but not to demineralization prevention. While the in vivo data ${ }^{1}$ clearly supports fluoridated milk as a public health intervention, it is still unclear as to whether milk follows a similar pattern in its fluoride delivery to other vehicles, such as toothpastes and rinses.

Consequently, the aims of the present in vitro study on caries lesion rehardening were two-fold: (a) to verify a fluoride dose-response relationship for fluoridated milk and (b) to investigate the effect of the application temperature of fluoridated milk.

\section{Materials and methods}

\subsection{Specimen preparation}

Enamel specimens were obtained from human permanent molars (only buccal and/or lingual surfaces were used) obtained from dental offices located in the USA. Tooth crowns were cut into $4 \mathrm{~mm} \times 3 \mathrm{~mm}$ specimens using a Buehler Isomet low-speed saw. The teeth were stored in deionized water saturated with thymol during the sample preparation process. Specimens were ground and polished to create flat, planar parallel dentine and enamel surfaces using a Struers Rotopol 31/Rotoforce 4 polishing unit (Struers Inc., Cleveland, PA, USA). The dentine side of the specimens was ground flat to a uniform thickness with 500-grit silicon carbide grinding paper. The enamel side of the specimen was serially ground using 1200, 2400 and 4000 grit paper. The specimens were then polished using a $1 \mu \mathrm{m}$ diamond polishing suspension on a polishing cloth. Resulting specimens had a thickness range of 1.7-2.2 mm. The specimens were assessed under a Nikon SMZ 1500 stereomicroscope at 20× magnification for cracks, hypomineralized (white spots) areas or other flaws in the enamel surface that would exclude them from use in the study. Prepared specimens were stored at $100 \%$ relative humidity at $4{ }^{\circ} \mathrm{C}$ until use. All specimens were prepared by the same, well-trained technicians using standard operating procedures. Eighteen specimens per treatment group were used for this study (based on a sample size calculation, data not shown).

\subsection{Artificial caries lesion formation}

Artificial caries lesions were formed in the enamel specimens by a 6-day immersion at $37^{\circ} \mathrm{C}$ in a solution containing $0.10 \mathrm{M}$ lactic acid, 0.20\% Carbopol C907, $4.1 \mathrm{mM} \mathrm{CaCl}{ }_{2} \cdot 2 \mathrm{H}_{2} \mathrm{O}, 8.0 \mathrm{mM}$ $\mathrm{KH}_{2} \mathrm{PO}_{4}$ adjusted to pH 5.0 (using $\mathrm{KOH}$ ). Lesions were stored at $100 \%$ relative humidity at $4{ }^{\circ} \mathrm{C}$ until use.

\subsection{Lesion baseline characterization}

The average specimen surface microhardness ( $\left.\mathrm{VHN}_{\text {base }}\right)$ after caries lesion formation was determined from four indentations on the surface of each specimen using a Vickers microhardness indenter at a load of $200 \mathrm{~g}$ for $15 \mathrm{~s}$. Only specimens with a $\mathrm{VHN}_{\text {base }}$ ranging from 35 to 65 were included in the study. Specimens were then assigned to groups and subgroups following a stratified randomization procedure, based on their $\mathrm{VHN}_{\text {base }}$. No sound enamel baseline hardness measurements were performed in the present study as these data were not needed in the calculation of rehardening efficiency and fluoride dose-response.

VHN was chosen instead of the 'gold-standard' technique transverse microradiography or cross-sectional microhardness as VHN was found to be more sensitive to detect differences between treatment groups in their ability to reharden incipient caries lesions when several of these techniques were used in the same study. ${ }^{12,13}$ Specimens employed in the present study were a subset of specimens prepared for an in situ study. The latter specimens were analyzed using transverse microradiography and presented typical subsurface caries lesions with the following mean lesion parameters: $\Delta Z=2300 \mathrm{vol} \% \min \mu \mathrm{m}$; $\mathrm{L}=72.8 \mu \mathrm{m}, \mathrm{SZ}_{\max }=49 \mathrm{vol} \% \mathrm{~min}$.

\section{4. $\quad$ pH cycling model}

A modified version of the $\mathrm{pH}$ cycling model developed by White ${ }^{14}$ was employed in the present study. The daily cyclic treatment regimen, which was repeated for $15 \mathrm{~d}$, consisted of a 4 - $h$ acid challenge in the lesion forming solution (10 am to $2 \mathrm{pm}$ ) and four, 10-min milk treatment periods ( $8 \mathrm{am}, 9 \mathrm{am}$, $3 \mathrm{pm}, 4 \mathrm{pm}$ ) with specimens stored in a 1:1 mixture of pooled human/artificial saliva all other times.

A 1:1 mixture of human saliva (wax-stimulated and from at least five healthy volunteers, pooled and refrigerated until use) and artificial saliva $(2.20 \mathrm{~g} / \mathrm{l}$ gastric mucin, $1.45 \mathrm{mM}$ $\mathrm{CaCl}_{2} \cdot 2 \mathrm{H}_{2} \mathrm{O}, 5.42 \mathrm{mM} \mathrm{KH}_{2} \mathrm{PO}_{4}, 6.50 \mathrm{mM} \mathrm{NaCl}, 14.94 \mathrm{mM} \mathrm{KCl}$ ) was used as the remineralization medium. Fresh saliva mixture was used each day (changed during the acid challenge period). The $\mathrm{pH}$ cycling phase was conducted at room temperature unless noted otherwise. Only the saliva mixture was stirred (350 rpm).

\subsection{Milk treatments}

Instant nonfat dry milk (Kroger Brand, USA) was reconstituted using deionized water and in a ratio as recommended by the manufacturer. Deionized water was used instead of tap water to avoid the introduction of a significant source of fluoride (tap water in the USA contains $0.7 \mathrm{mg} / \mathrm{l}$ fluoride). Fluoride (F) was added as sodium fluoride and using a $1000 \mathrm{mg} / \mathrm{l} \mathrm{F}$ solution to prepare milk with the following fluoride concentrations: 0 (placebo, no F added); 2.5; 5; 10; 20 mg/l. Fresh milk samples were prepared just prior to each treatment. Milk was used at room temperature (measured to be $22 \pm 1{ }^{\circ} \mathrm{C}$ during the course of the study). Fluoridated milk at $10 \mathrm{mg} / \mathrm{l} \mathrm{F}$ was also employed at 4 and $60^{\circ} \mathrm{C}$ to resemble 'refrigerated' and 'hot' milk. A temperature of $60^{\circ} \mathrm{C}$ was chosen as it was found to be the mean preferred temperature for drinking coffee in a consumer study. ${ }^{15}$ For temperature-adjusted treatments, non-fluoridated, reconstituted milk and F solutions were cooled or heated to the desired temperature before being mixed and used immediately thereafter. After treatments, specimens were rinsed briefly under running deionized water before being placed back into the saliva mixture. 


\subsection{Post- $p H$ cycling lesion characterization}

The mean $\mathrm{VHN}_{\text {post }}$ of each specimen was determined, as described above, from four indentations on the surface of each specimen, next to the baseline indentations. The change in VHN vs. lesion baseline was calculated as follows: $\Delta \mathrm{VHN}=\mathrm{VHN}_{\text {post }}-\mathrm{VHN}_{\text {base }}$. Each specimen served as its own control.

\subsection{Enamel fluoride uptake (EFU)}

After the $\mathrm{VHN}_{\text {post }}$ measurements, the fluoride content of each enamel specimen was determined using the microdrill technique ${ }^{16}$ to a depth of $100 \mu \mathrm{m}$. The diameter of the drill hole was determined. The enamel powder from the drill hole was collected, dissolved $\left(20 \mu \mathrm{l}\right.$ of $\mathrm{HClO}_{4}+40 \mu \mathrm{l}$ citrate/EDTA buffer $+40 \mu \mathrm{l}$ deionized water) and analyzed for fluoride by comparison to a similarly prepared standard curve. Fluoride

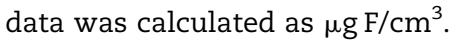

\subsection{Statistical analysis}

The variables $\triangle$ VHN and EFU were calculated for each specimen and analyzed using a one-way analysis of variance (ANOVA) model after normal distribution of the data was confirmed (Shapiro-Wilk test). $\Delta$ VHN was the primary variable. Where significant differences were indicated, the individual means were analyzed by Fisher's Least Significant Difference test. The significance level for the analyses was set at $5 \%$.

\section{Results}

$\mathrm{VHN}_{\text {base }}$ were virtually identical between treatment groups (mean range 49.0-49.8). The results and statistical analyses for both study variables can be found in Table 1 . A linear F doseresponse was established for both the $\Delta \operatorname{VHN}\left(R^{2}=0.89\right)$ and EFU data $\left(R^{2}=0.94\right)$. Likewise, a linear dose-response was established for temperature vs. $\Delta$ VHN $\left(R^{2}=0.92\right)$ and vs. EFU $\left(R^{2}=0.99\right)$ for the $10 \mathrm{mg} / \mathrm{l} \mathrm{F}$ treatment groups. Both data sets showed that higher $\mathrm{F}$ concentrations and higher milk temperatures resulted in more rehardening and higher EFU. The $\triangle$ VHN and EFU data were only weakly correlated (Pearson's correlation of 0.51).

Table 1 - Means \pm standard deviations and results of the statistical analyses for all study variables $(n=18$ per treatment group).

\begin{tabular}{lccl}
$\begin{array}{l}\text { F in milk } \\
{[\mathrm{mg} / \mathrm{l}]}\end{array}$ & $\begin{array}{c}\text { Milk temp. } \\
{\left[{ }^{\circ} \mathrm{C}\right]}\end{array}$ & $\Delta$ VHN & EFU $\left[\mu \mathrm{g} \mathrm{F} / \mathrm{cm}^{3}\right]$ \\
\hline 0 & 22 & $2.6 \pm 7.1 \mathrm{E}^{\mathrm{a}}$ & $075 \pm 137 \mathrm{D}$ \\
2.5 & 22 & $8.9 \pm 9.4 \mathrm{CD}$ & $196 \pm 89 \mathrm{D}$ \\
5 & 22 & $12.2 \pm 6.1 \mathrm{CD}$ & $356 \pm 140 \mathrm{C}$ \\
10 & 4 & $8.3 \pm 5.5 \mathrm{D}$ & $513 \pm 242 \mathrm{~B}$ \\
10 & 22 & $14.0 \pm 4.5 \mathrm{BC}$ & $598 \pm 153 \mathrm{~B}$ \\
10 & 60 & $18.7 \pm 12.2 \mathrm{AB}$ & $740 \pm 195 \mathrm{~A}$ \\
20 & 22 & $20.3 \pm 10.5 \mathrm{~A}$ & $789 \pm 325 \mathrm{~A}$ \\
\hline
\end{tabular}

a Significant differences between treatment groups are highlighted by different letters.

\section{Discussion}

Milk is by no means the ideal delivery vehicle for fluoride: its calcium content can lead to decreases in F bio availability over time, ${ }^{17}$ and as milk is intended to be consumed primarily by children, the risk of fluorosis and fluoride toxicity must be considered. The American Academy of Pediatrics proposed a daily fluoride dose of between 0.05 and $0.07 \mathrm{mg} \mathrm{F} / \mathrm{kg}$ body weight/day, ${ }^{18}$ which is generally accepted as 'a useful upper limit for fluoride intake by children'. ${ }^{19}$ Bearing this upper limit in mind, milk fluoride concentrations as high as $8-10 \mathrm{mg} / \mathrm{l}$ (depending on body weight) could be supported for children older than eight. In adults, a tolerable upper intake level of $10 \mathrm{mg}$ fluoride per day was recommended by the US Institute of Medicine in $1997,{ }^{20}$ thereby allowing additional room for investigation.

Milk has several advantages over conventional fluoridated oral care products, such as mouthwashes and toothpastes. Intra-oral contact times are considerably longer for milk as it is typically consumed over longer periods of time ( $\geq 10 \mathrm{~min}$ vs. $\leq 2 \mathrm{~min}$ for rinses, toothpastes). Milk is palatable over a wide temperature range, and fluoridated milk can be easily prepared 'on-site' (especially when powdered milk is used) to name only a few of its advantages which have made it a successful public health measure.

The present study has shown (Table 1 ) that - given the limitations of the study - an increase in milk fluoride concentration can lead to more rehardening of incipient caries lesions which is paired with an increased F accumulation in the lesions. These results; i.e. a F dose-response, were in agreement with a previous in vitro study ${ }^{8}$ and somewhat mirror those observed for toothpastes clinically, ${ }^{21}$ highlighting similarities between these different $F$ vehicles. The perhaps more interesting result of the present study was that an increase in milk temperature can also enhance, and vice versa decrease in temperature diminish F efficacy. These observations can be explained by increased mobility of the F ion with increasing temperature, ${ }^{22}$ providing findings from aqueous solutions can be extrapolated to milk, and/or an increased reaction rate of fluoride with mineral as the temperature increases. However, milk consumed at elevated or lower temperatures will not remain at these temperatures in the oral cavity for long. Likewise, it must also be noted in this context that numerical differences in EFU between treatment groups in the present study were relatively small. Reasons could be two-fold: (a) the employed low F concentrations simply do not allow for more rehardening to occur and (b) in vitro caries models do not take into systemic effects into account which have to be considered for fluoridated milk. The presently used model was modified and milk treatment times of 10 min were employed to maintain some physiological relevance, although considerably longer treatment times could have been justified based on other previous studies. ${ }^{11,23}$ The total number of treatments during the course of the study $(4 \times / d$ over $15 d=60$ treatments) is somewhat equivalent to three months of fluoridated milk use (assuming $1 \times / d$ and $5 d$ /week). Considering that in vitro research often overestimates in vivo effects, it remains to be seen if the present findings can be extrapolated and applied to current milk fluoridation programmes, by 
perhaps providing hot fluoridated milk in insulated mugs in future.

Further studies to evaluate the effect of temperature on $\mathrm{F}$ efficacy should focus on the intra-oral uptake to and retention of $\mathrm{F}$ in plaque and plaque fluid before confirming present results using clinically relevant in situ caries models. Likewise, potential adverse effects on $\mathrm{F}$ toxicity in relation to its delivery temperature will have to be studied. Furthermore, the impact of different milk sources (pasteurized, UHT, powder, various fat contents) and F salts (sodium monofluoro phosphate) on the present findings needs to be investigated.

\section{Conclusions}

The present in vitro study has shown that incipient caries lesion rehardening is influenced by fluoride concentration in milk and its application temperature. Lesion rehardening and fluoride accumulation were found to follow a dose-response relationship. The efficacy of fluoridated milk was enhanced by an increase in milk application temperature. However, caution must be issued as laboratory research often overestimates in vivo effects. Hence, present results will have to be confirmed using more physiologically relevant in situ and in vivo models representative of the caries process.

\section{Declaration of interests}

The authors declare that there is no conflict of interest.

This study was solely funded by the Oral Health Research Institute Remineralization Research Programme.

\section{R E F E R E N C E S}

1. Banoczy J, Petersen PE, Rugg-Gunn AJ, editors. Milk fluoridation for the prevention of dental caries. Geneva: WHO Press; 2009. http://whqlibdoc.who.int/publications/2009/ 9789241547758_eng.pdf [checked 27.03.12]..

2. European Academy of Paediatric Dentistry. Guidelines on the use of fluoride in children: an EAPD policy document. European Archives of Paediatric Dentistry 2009;10:129-35.

3. Duckworth RM, Stewart D. Effect of mouthwashes of variable $\mathrm{NaF}$ concentration but constant $\mathrm{NaF}$ content on oral fluoride retention. Caries Research 1994;28:43-7.

4. Zero DT, Creeth JE, Bosma ML, Butler A, Guibert RG, Karwal $\mathrm{R}$, et al. The effect of brushing time and dentifrice quantity on fluoride delivery in vivo and enamel surface microhardness in situ. Caries Research 2010;44:90-100.

5. Chesters RK, Huntington E, Burchell CK, Stephen KW. Effect of oral care habits on caries in adolescents. Caries Research 1992;26:299-304.
6. Mellberg JR, Loertscher KL. Fluoride acquisition in vitro by sound human tooth enamel from sodium fluoride- and ammonium silicofluoride-phosphate solutions. Archives of Oral Biology 1972;17:1107-16.

7. Purdell-Lewis DJ, Arends J, Schuthof JA. $\mathrm{SnF}_{2}$ treatment of enamel, hydroxyapatite or brushite at $37^{\circ} \mathrm{C}$ and $50^{\circ} \mathrm{C}$ : an infra-red investigation. Journal de BiologieBuccale 1979;7:179-90.

8. Malinowski M, Toumba KJ, Strafford SM, Duggal MS. Effect of varying concentrations of fluoridated milk on enamel remineralisation in vitro. Caries Research 2008;42:234.

9. Malinowski M, Duggal MS, Strafford SM, Toumba KJ. Effect of two different concentrations of fluoride in fluoridated milk on enamel hardness in situ. Caries Research 2009;43:220.

10. Malinowski M, Duggal MS, Strafford SM, Toumba KJ. Effect of two different concentrations of fluoridated milk on enamel remineralisation in situ. Caries Research 2010;44:203.

11. Itthagarun A, Verma S, Lalloo R, King NM, Wefel JS, Nair RG. Effects of fluoridated milk on artificial enamel carious lesions: a pH cycling study. Journal of Dentistry 2011;39:817-24.

12. Lippert F, Newby EE, Schemehorn BR. Efficacy of fluoride dentifrices in a de-/remineralization caries cycling model investigated using multiple interrogation techniques. Caries Research 2008;42:207.

13. Churchley D, Lynch RJM, Lippert F, Eder JSO, Alton J, Gonzalez-Cabezas C. Terahertz pulsed imaging study to assess remineralization of artificial caries lesions. Journal of Biomedical Optics 2011;16:026001.

14. White DJ. Reactivity of fluoride dentifrices with artificial caries. 1. Effects on early lesions - F-uptake, surface hardening and remineralization. Caries Research 1987;21:126-40.

15. Lee HS, O'Mahony M. At what temperatures do consumers like to drink coffee? Mixing methods. Journal of Food Science 2002;67:2774-7.

16. Sakkab NY, Cilley WA, Haberman JP. Fluoride in deciduous teeth from an anti-caries clinical study. Journal of Dental Research 1984;63:1201-5.

17. Duff EJ. Total and ionic fluoride in milk. Caries Research 1981;15:406-8.

18. American Academy of Pediatrics. Committee on nutrition, fluoride supplementation. Pediatrics 1986;77:758-61.

19. Burt BA. The changing patterns of systemic fluoride in take. Journal of Dental Research 1992;71(special issue):1228-37.

20. IOM (Institute of Medicine). Dietary reference intakes for calcium, phosphorus, magnesium, vitamin D, and fluoride. The National Academies Press; 1997. Online access: http:// www.nap.edu/openbook.php?record_id=5776..

21. Walsh T, Worthington HV, Glenny A-M, Appelbe P, Marinho VC, Shi X. Fluoride toothpastes of different concentrations for preventing dental caries in children and adolescents. Cochrane Database of Systematic Reviews 2010;1:CD007868.

22. Mallanoo T, Stokes RH. The temperature dependence of the mobility of aqueous fluoride ion, and the apparent molar volume of sodium fluoride. Australian Journal of Chemistry 1977;30:1375-7.

23. Ivancakova R, Hogan MM, Harless JD, Wefel JS. Effect of fluoridated milk on progression of root surface lesions in vitro under $\mathrm{pH}$ cycling conditions. Caries Research 2003;37:166-71. 